\title{
Posterior Tibial Artery Branch
}

National Cancer Institute

\section{Source}

National Cancer Institute. Posterior Tibial Artery Branch. NCI Thesaurus. Code C33385.

Any artery arising from the posterior tibial artery. 